\title{
High strength glass beads coated with CNT/rGO incorporated urethane coating for improved crush resistance for effective hydraulic fracturing
}

\author{
Umair Ishtiaq ${ }^{1} \cdot$ Ali Aref $^{1} \cdot$ Ali Samer Muhsan $^{2} \cdot$ Ahmed Rashid $^{1} \cdot$ Sinan S. Hamdi ${ }^{3}$
}

Received: 2 September 2021 / Accepted: 20 January 2022 / Published online: 15 February 2022

(c) The Author(s) 2022

\begin{abstract}
Hydraulic fracturing is a widely employed well stimulation technique in which a synthesized fracking fluid is pumped into the well bore at high pressures to propagate fractures in rock formation matrix for hydrocarbon production. Proppant being one of the essential component of fracturing fluid is used to keep the hydraulically induced fractures open and conductive by acting as a mechanically strong support particle. Hydraulic fracturing operations are gradually shifting into deeper and low permeability (tight) formation at elevated temperature and pressure conditions at which conventionally used silica sand is becoming unviable as proppant due to its crushing. For resin-coated sand (RCS), temperatures greater than $60^{\circ} \mathrm{C}$ under high pressures, the glass transition temperature ( $\mathrm{Tg}$ ) threshold limit of polyurethane-based resin coating is reached at which this applied coating tends to soften that results reduction in the mechanical strength of the coated sand pack. Glass beads are also considered as good contestant for proppant that were selected in this study due to their high roundness and sphericity. They were drip coated with urethane resin incorporated with three different concentrations of $0.1 \mathrm{wt} \%, 0.5 \mathrm{wt} \%$ and $1 \mathrm{wt} \%$ carbon nanotubes (CNTs) and reduced graphene oxide ( $\mathrm{rGO}$ ) nanofillers, respectively. Crush test analysis by means of Universal Testing Machine (UTM) revealed significant improvement in the mechanical strength of coated glass bead proppants. $0.5 \mathrm{wt} \%$ loading of CNTs into urethane resin proved to be the best optimum concentration at which the mechanical strength of the coated glass bead improved by $84 \%$ along with $40 \%$ reduction in fines generation due to its containment within the applied coating. Crush test results also further revealed that nanofillers concentration loadings greater than the optimum threshold limit into urethane resin promoted their mutual agglomeration that resulted in profound reduction in mechanical strength of coated glass beads therefore resulting in more crushing and higher generation of undesired and detrimental fine particles.
\end{abstract}

Keywords Proppant $\cdot$ Hydraulic fracturing $\cdot$ Nanofillers $\cdot$ Urethane resin $\cdot$ Carbon nanotubes (CNTs) $\cdot$ Reduced graphene oxide (rGO) · Compressive strength

\section{Introduction}

Hydraulic fracturing is an essential stimulation technique employed to increase hydrocarbon production from the reservoir to the near well-bore region (Barati and Liang 2014; Liang et al. 2016). This fracturing process involves pumping

Umair Ishtiaq

umair.ishtiaq_g02875@utp.edu.my

1 Petroleum Engineering Department, Universiti Teknologi PETRONAS (UTP), Seri Iskandar, Malaysia

2 Mechanical Engineering Department, Universiti Teknologi PETRONAS (UTP), Seri Iskandar, Malaysia

3 Fundamental and Applied Sciences Department, Universiti Teknologi PETRONAS (UTP), Seri Iskandar, Malaysia a synthesized fracturing fluid at high pressures into the oil and gas-bearing rock formation, causing it to fissure creating inter-connected fracture channel pathways as passage for the entrapped hydrocarbon to flow out. To keep the induced fractures conductive and prevent them from closing (sealing) under cyclic fracture closure stress, proppants are inserted as solid support particles that deposits in the fracture to form a proppant pack.

Proppants materials can be generally classified as conventional or advanced (Liang et al. 2016; Pangilinan et al. 2016). Sand, gravel, walnut shell, glass beads, aluminum and plastic pellets etc. fall under the umbrella of conventional proppants, whereas polymer-coated ceramic-based proppants fall under the realm of advanced proppants (Liang et al. 2016; Campos and Sansone 2018). The ideal propping 
agent must be mechanically strong resistant to crushing with uniform sphericity and roundness for high conductivity (Speight 2016).

The main problem associated with proppants is their friability (crushing). Proppants crush when they are overstressed, causing the generation of unwanted and detrimental fines that can reduce proppant pack conductivity leading to reduction in hydrocarbon production. Glass bead as proppants are famous as they have uniform shape and size and are well sorted. They have been used commercially for over ten years as a partial replacement for conventionally used silica sand, but there is substantial evidence indicating that the strength of the glass in multilayers is greatly decreased in the presence of brine at elevated temperature and pressure conditions (Cooke 1977).

To mitigate this issue, coatings are generally applied on the proppant's surface with polymer resins (Liang et al. 2016; Pangilinan et al. 2016; Zoveidavianpoor and Gharibi 2015). These types of proppants fall under the category of resincoated proppants (RCP). The curing of resin coating at certain temperatures, pressures and in the presence of curatives forms three-dimensional cross-linked structures that offer superior proppant properties (Liang et al. 2016) in terms of improved mechanical strength (less crushing) and lower degradation. The core advantage of resin coat proppants is to create a protective polymeric coating around proppant grain substrate that reduces proppant crushing by inducing mutual adhesion in the form of grain-to-grain bonding making the proppant pack a well-connected mass that effectively distributes the fracture closure stress among the proppant pack and therefore resists closure of the fracture. The fines generated by proppant crushing can be effectively entrapped within the applied resin coating as shown in Fig. 1.

Resin system is generally of two types, i.e., curable and pre-cured. Curable resins are used to prevent proppant flowback by consolidating the proppants, whereas pre-cured resins are used to trap the fines generated by the proppants. However, these cured cross-linked polymeric coatings undergo slight softening at elevated temperatures at a point known as glass transition temperature ( $\mathrm{Tg}$ ) (Liang et al. 2016). At temperatures higher than $\mathrm{Tg}$, the mobility of the polymer chains of a cured resin coating increases, altering the nature of the applied coating from rig to a rubbery state. This softening of the coated resin system reduces the mechanical strength of the proppant pack.

In recent years, polymeric proppant coating techniques have involved nanomaterials that offer enticing characteristics. Researchers have reported advantages of incorporating carbon-based nanomaterials to enhance properties of resin-coated proppants. Glass fibers were generally favored because of its performance and low cost as it does not require shut-in time or curing temperature and does not interact with common fracturing fluid additives (Pangilinan et al. 2016), but they are no longer used due to brittle in nature and can be dissolved in the formation. A nanocomposite of phenolic formaldehyde (novolac) resin coated proppant was reported that used hexamethylenetetramine as crosslinker, wettability altering agents and CNTs as nanoreinforcing agents to improve the mechanical strength of sand coated proppants (Haque et al. 2019). Fiber incorporated phenolic-aldehyde polymer coating method on sand substrate for improved grain strength and reduced flow back control via fiber interlocking was reported (Hussain et al. 2015). The incorporation of functionalized graphene nanoplatelets (GNPs) into proppant resin coatings as a nanofiller to enhance the mechanical strength and thermal conductivity was reported (Tabatabaei et al. 2019).

This study investigates the improvement in the mechanical strength of non-toxic polyurethane-based coated glass bead proppants by incorporating MWCNTs and reduced graphene oxide (rGO) as reinforcement fillers. In addition, the ability of the applied composite coating to contain (entrap) generated fines is also investigated.

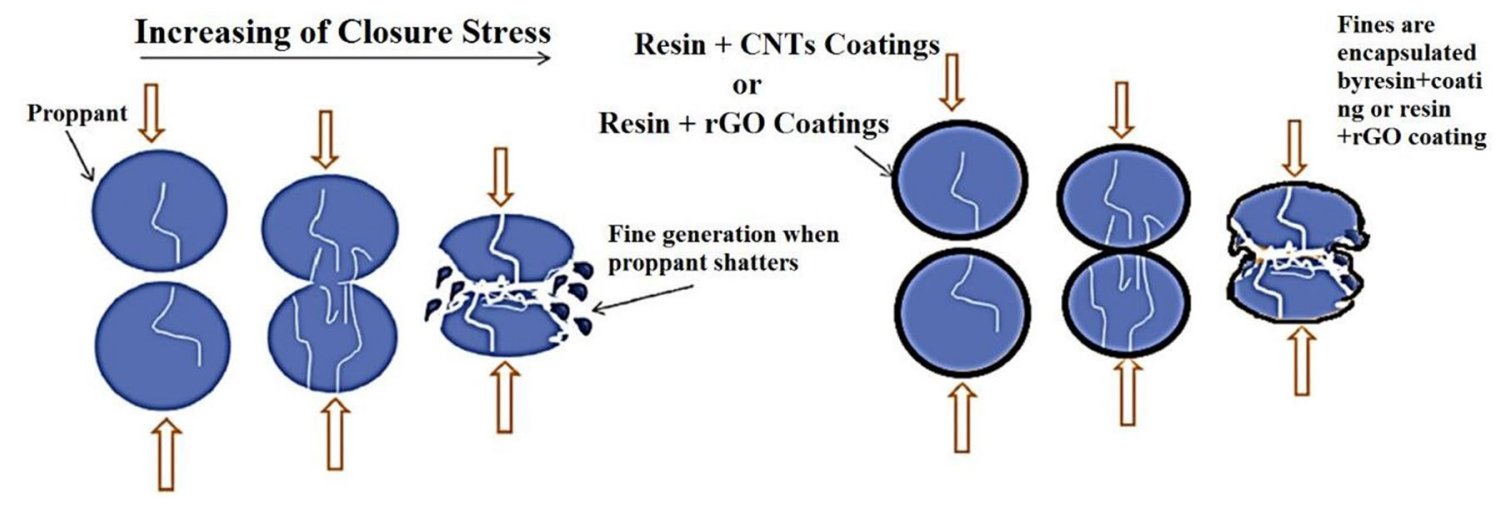

Fig. 1 Fines containment within proppant body due to nanomaterial incorporated applied polyurethane resin coating (Modified from Zoveidavianpoor and Gharibi 2015) 


\section{Materials and methods}

\section{Materials}

Glass beads as proppant and acetone as dispersing solvent were used as available. Polyurethane was obtained from Weifong waterproof materials Co. Ltd. Multi-wall carbon nanotubes (MWCNTs) with length between 0.5-2-micron, outer diameter between 30 to $50 \mathrm{~nm}$ and surface area of $60 \mathrm{~m}^{2} / \mathrm{g}$ and reduced graphene oxide (rGO) were obtained from Sigma Aldrich Houston, TX, USA. All the materials were used as received.

\section{Method}

\section{Glass beads coating with urethane resin incorporated with CNTs}

Three separate CNTs solutions with $0.1 \mathrm{wt} \%, 0.5 \mathrm{wt} \%$ and $1 \mathrm{wt} \%$ concentrations were mixed with acetone followed by mechanical dispersion by means of a probe sonicator for 5 minutes. Two equal volumes of aqueous polyurethane were prepared namely urethane A and urethane B with the purpose to prepare dispersed CNTs solutions by reducing the agglomeration potential. In urethane A solution, the dispersed solutions of acetone and CNTs were added followed by sonication for 5 minutes. In urethane $\mathrm{B}$, the prepared dispersed solutions of acetone and CNTs were added followed by simple mixing. Prepared urethane B solution was added to the previously prepared urethane A solutions followed by sonication for 5 minutes. The resultant dispersed and mixed solution were labelled as solution C-1, C-2 and C-3. The uncoated glass bead proppants were coated by placing them on a sieve paper followed by dripping solution $\mathrm{C}-1, \mathrm{C}-2$ and $\mathrm{C} 3$ onto them by the aid of a dropper. The excess solution flowed through the siever strainer leaving behind coated glass beads. These coated glass beads were left at room temperature for 1 hour to be dried and to be cured as shown in Fig. 2.

\section{Glass beads coating with urethane resin incorporated with rGO}

The process of coating the glass beads with resin containing rGO was akin to that of coating glass beads with resin containing CNTs. rGO was present in a well-mixed solution form and no need for its dispersion by means of sonication was required. Likewise, urethane was equally divided into two equal volumes namely urethane $\mathrm{A}$ and urethane $\mathrm{B}$. Two separate solutions were prepared by mixing acetone in urethane A followed by mixing three separate concentrations of $0.1 \mathrm{wt} \%, 0.5 \mathrm{wt} \%$ and $1 \mathrm{wt} \%$ of rGO in urethane B. The prepared urethane B solutions were added and mixed separately with the prepared urethane $\mathrm{A}$ solution thereby preparing resultant solution labelled as $\mathrm{C}-1, \mathrm{C}-2$ and $\mathrm{C}-3$. The resultant solutions $\mathrm{C} 1$ to $\mathrm{C} 3$ were drip coated onto uncoated glass beads with the excess solution flowing through the strainer holding the coated glass beads. These coated glass beads were left at room temperature for 1 hour to be dried as shown in Fig. 3.

\section{Crushing test}

Universal Testing Machine (UTM) that complied with Proppant Standard ISO 13503-2 (ISO 2006) was used to perform all proppant crush test as shown in Fig. 4. The UTM machine exerts vertical stress onto the proppants to determine the compressive strength of the coated and uncoated proppants. A single even layer of proppant was prepared inside the stainless steel mold closed by a plunger. More than one layer of proppant will affect the compressive strength of proppants. It is then placed in between the top and bottom plate of the UTM machine. Load was applied till
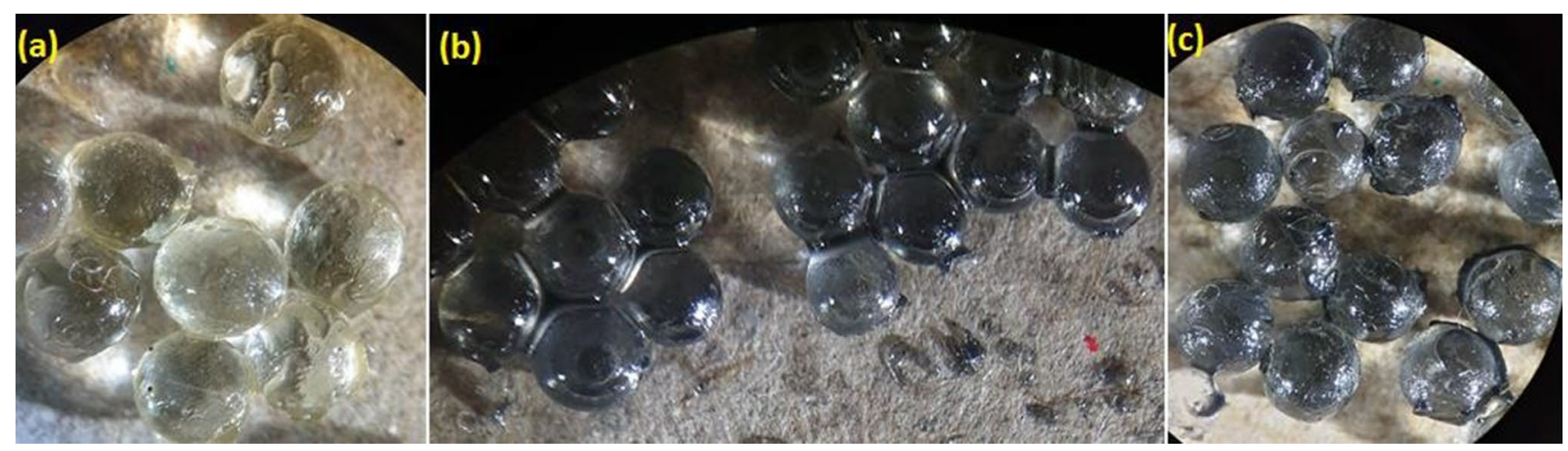

Fig. 2 Glass beads urethane coated proppants containing a $0.1 \% \mathrm{CNTs}, \mathbf{b} 0.5 \% \mathrm{CNTs}$ and $\mathbf{c} 1 \% \mathrm{CNTs}$ 

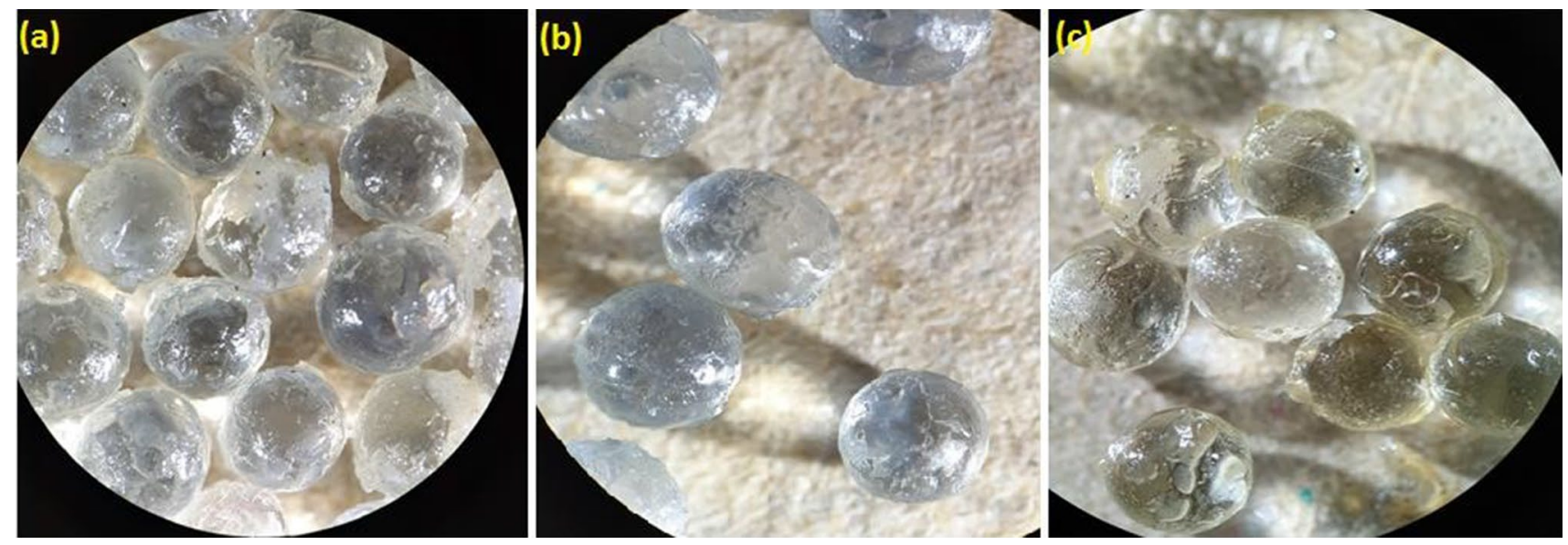

Fig. 3 Glass beads urethane coated proppants containing a $0.1 \%$ rGO, b $0.5 \%$ rGO and $\mathbf{c} 1 \%$ rGO

Fig. 4 Universal Testing Machine (UTM)

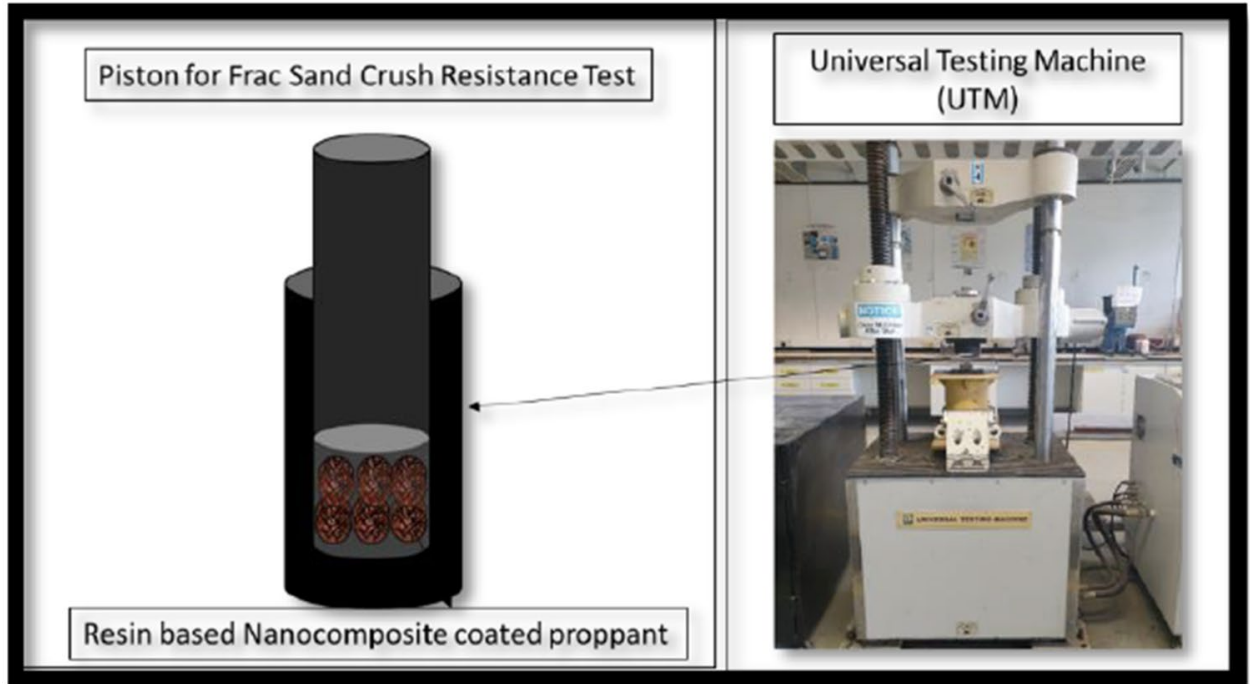

all the proppants were crushed. The results were presented in a stress vs deformation graph with the maximum load $(\mathrm{kN})$ and compression strength (MPa).

\section{Measurement of \% fines generated using 400 mesh siever}

A 400 mesh siever was used to determine the amount of fines generated by coated and uncoated glass bead proppants after the crush test. Any crushed proppants smaller than 40 mesh size were considered as fines. The percentage of fines generated refers to the mass percentage and is determined by using the equation below: fines that are smaller than 40 mesh size. After sieving, the fines that were smaller than 40 mesh size were weighted and the percentage of fines generated for each coated glass bead proppants and uncoated glass bead proppants was obtained.

\section{Results and discussion}

\section{UTM crush test of CNT-urethane coated glass beads}

From Table 1 and Fig. 5, it can be clearly noticed that the uncoated glass bead proppants have the lowest compressive

$\%$ of fines generated $=($ Mass of crushed proppants $(g)) /($ Total mass $(\mathrm{g})) \times 100$

where the total mass is the mass of proppants used before the crush test and the mass of crushed proppants are the mass of strength compared to the urethane-CNTs coated proppants. This is because the uncoated proppants are devoid of any 
Table 1 Compressive strength of each concentration of CNTs coated glass bead proppants

\begin{tabular}{lcllll}
\hline $\begin{array}{l}\text { Concentration of CNTs } \\
(\%) \text { in urethane resin }\end{array}$ & $\begin{array}{l}\text { Max load } \\
\text { applied (kN) }\end{array}$ & $\begin{array}{l}\text { Compressive } \\
\text { strength (MPa) }\end{array}$ & $\begin{array}{l}\text { Increase in com- } \\
\text { pressive strength } \\
(\%)\end{array}$ & $\begin{array}{l}\text { Fines gen- } \\
\text { erated }(\mathrm{g})\end{array}$ & $\begin{array}{l}\text { Fines } \\
\text { generated } \\
(\%)\end{array}$ \\
\hline Uncoated & 9.183 & 2923.125 & - & 0.3301 & 6.15 \\
0.1 & 12.847 & 4089.387 & 39.90 & 0.2553 & 4.76 \\
0.5 & 16.868 & 5369.251 & 83.68 & 0.1954 & 3.64 \\
1.0 & 13.536 & 4308.56 & 47.40 & 0.0736 & 1.37 \\
\hline
\end{tabular}

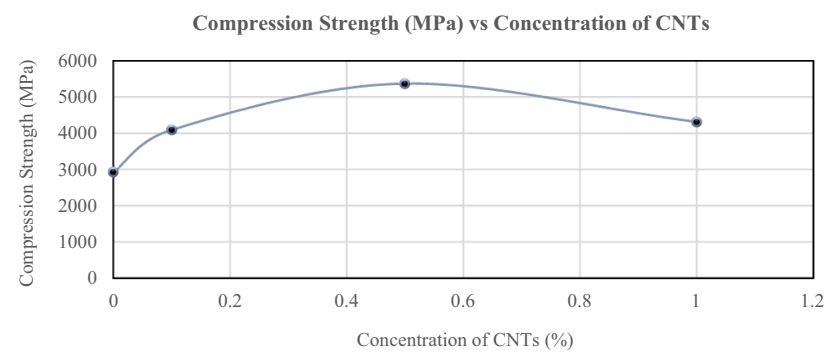

Fig. 5 Compressive strength of uncoated proppants with different concentration of CNTs coated proppants

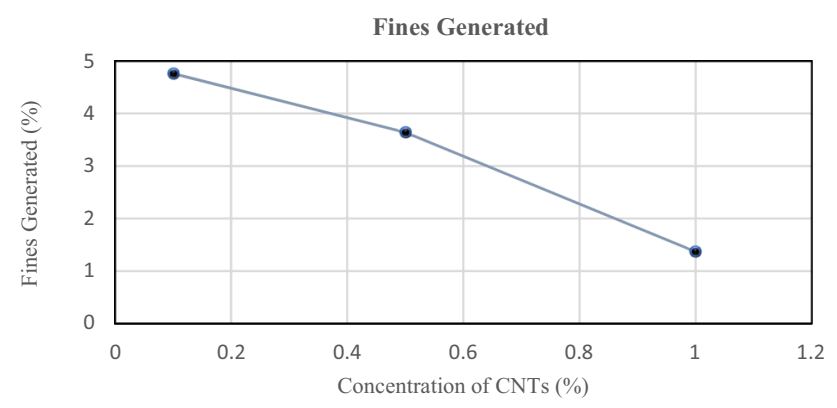

Fig. 6 Generation of fines at different CNT loading in urethane coatings

protective polymeric coating, and hence, they are easily crushed at a low applied load. $0.5 \%$ CNTs coated proppants showed the highest compressive strength when compared to the $0.1 \%$ and $1 \%$ urethane-CNTs coated glass beads. In the beginning, the compressive strength of proppants increases as the concentration of CNTs increase. CNTs act as reinforcing fibers in resin system. However, after $0.5 \% \mathrm{CNTs}$, it is noticed that the compressive strength of CNTs coated proppants started to decline. This is due to the agglomeration of CNTs on the surface of the proppant coating. Agglomeration causes uneven surface coating on the proppant's substrate. When pressure was applied on the proppants, the surface part that has thinner coating than the agglomerated part tends to break first. This will cause the proppants to have lower compressive strength. Fines generation due to proppant crushing was significantly reduced by the application of urethane coating that effectively contains it within the proppant body. Fine containment becomes more profound as the concentration of CNTs increases that strengthens the urethane coating resulting is lesser crushing of proppant grains as shown in Fig. 6. In addition, CNTs form a fiber web that adds to preventing the release of fines. Thus, the most suitable CNTs concentration for proppant coatings is $0.5 \%$

\section{Fines generation}

Fines generation due to proppant crushing was significantly reduced by the application of urethane coating that effectively contains them within the proppant body. Fine containment becomes more profound as the concentration of CNTs increases that strengthens the urethane coating resulting is lesser crushing of proppant grains as shown in Fig. 6. In addition, CNTs form a fiber web that adds to preventing the release of fines. Thus, the most suitable CNTs concentration for proppant coatings is $0.5 \%$

\section{UTM crush test of rGO-urethane coated glass beads}

For rGO-urethane coated proppants, it is noticed that $0.1 \%$ rGO loading gives the highest compressive strength
Table 2 Compressive strength of each concentration of rGO coated glass bead proppants

\begin{tabular}{llllll}
\hline $\begin{array}{l}\text { Concentration of } \\
\text { rGO }(\%)\end{array}$ & $\begin{array}{l}\text { Max load } \\
\text { applied }(\mathrm{kN})\end{array}$ & $\begin{array}{l}\text { Compressive } \\
\text { strength (MPa) }\end{array}$ & $\begin{array}{l}\text { Increase in compres- } \\
\text { sive strength }(\%)\end{array}$ & $\begin{array}{l}\text { Fines gener- } \\
\text { ated }(\mathrm{g})\end{array}$ & $\begin{array}{l}\text { Fines } \\
\text { generated } \\
(\%)\end{array}$ \\
\hline Uncoated & 9.183 & 2923.125 & - & 0.3301 & 6.15 \\
0.1 & 12.957 & 4124.395 & 41.10 & 0.1863 & 3.47 \\
0.5 & 11.832 & 3766.278 & 28.84 & 0.4255 & 4.95 \\
1.0 & 11.285 & 3592.182 & 22.89 & 0.2963 & 5.52 \\
\hline
\end{tabular}




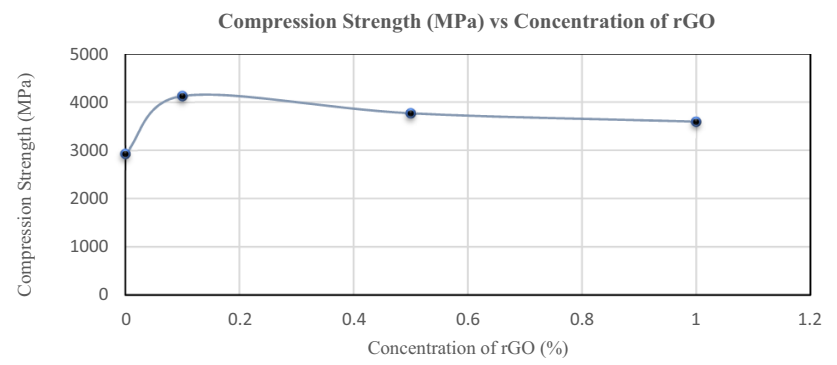

Fig. 7 Compressive strength of uncoated proppants with different concentration of rGO coated proppants

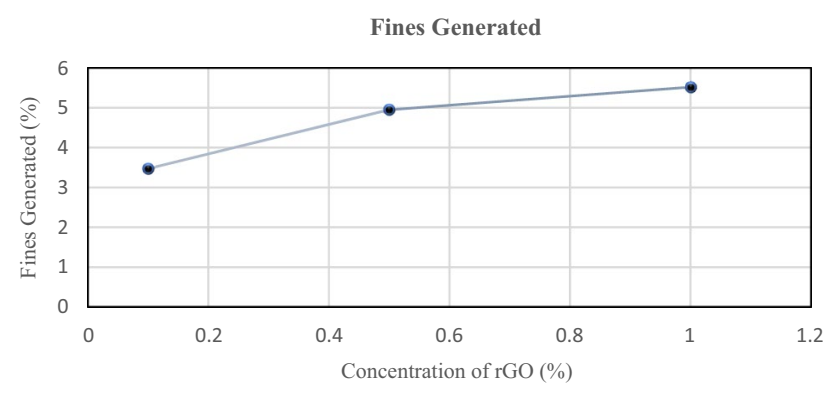

Fig. 8 Generation of fines at different rGO loading in urethane coatings

compared to other concentration of rGO-urethane coated proppants as shown in Table 2 and Fig. 7. It is also noticed that the uncoated proppants still had the lowest compressive strength among all the rGO-urethane coated proppants. The compressive strength of rGO-urethane coated proppants starts to decrease after $0.1 \%$ rGO loading. As the loading concentration of rGO increases in the urethane coating, the attractive hydrogen bonding among the rGO layers increases resulting in its agglomeration (Tran et al. 2012). The uneven coating surface layer formed by rGO agglomeration causes crushing of proppant under the application of load stress.

\section{Fines generation}

As shown in Fig. 8, least amount of fines were generated at $0.1 \%$ rGO loading in urethane coating. The trend for percentage of fines generated for proppant coated with rGOurethane is opposite from the trend for percentage of fines generated for proppant coated with CNTs-urethane. Higher concentration of rGO loading into urethane resin leads to higher the percentage of fines generated. The main reason for high fine generation at higher rGO loadings into urethane resin can be attributed to high degree of rGO agglomeration that forms highly uneven surface coating. Higher rGO loadings non-uniformly cover (due to high agglomeration) the proppant surface that fails to effectively distribute the applied load resulting in greater crushing of the proppant grain.

\section{FESEM analysis}

Overall, it is noticed that both CNTs and rGO coated glass bead proppants can trap fines by sticking fines on the surface of the coatings. However, CNTs based coating shows noticeable reduction of fines generated due to crushing by improving the compressive strength and encapsulating the fines as shown in Fig. 9. Incorporated CNTs and rGO nanofillers

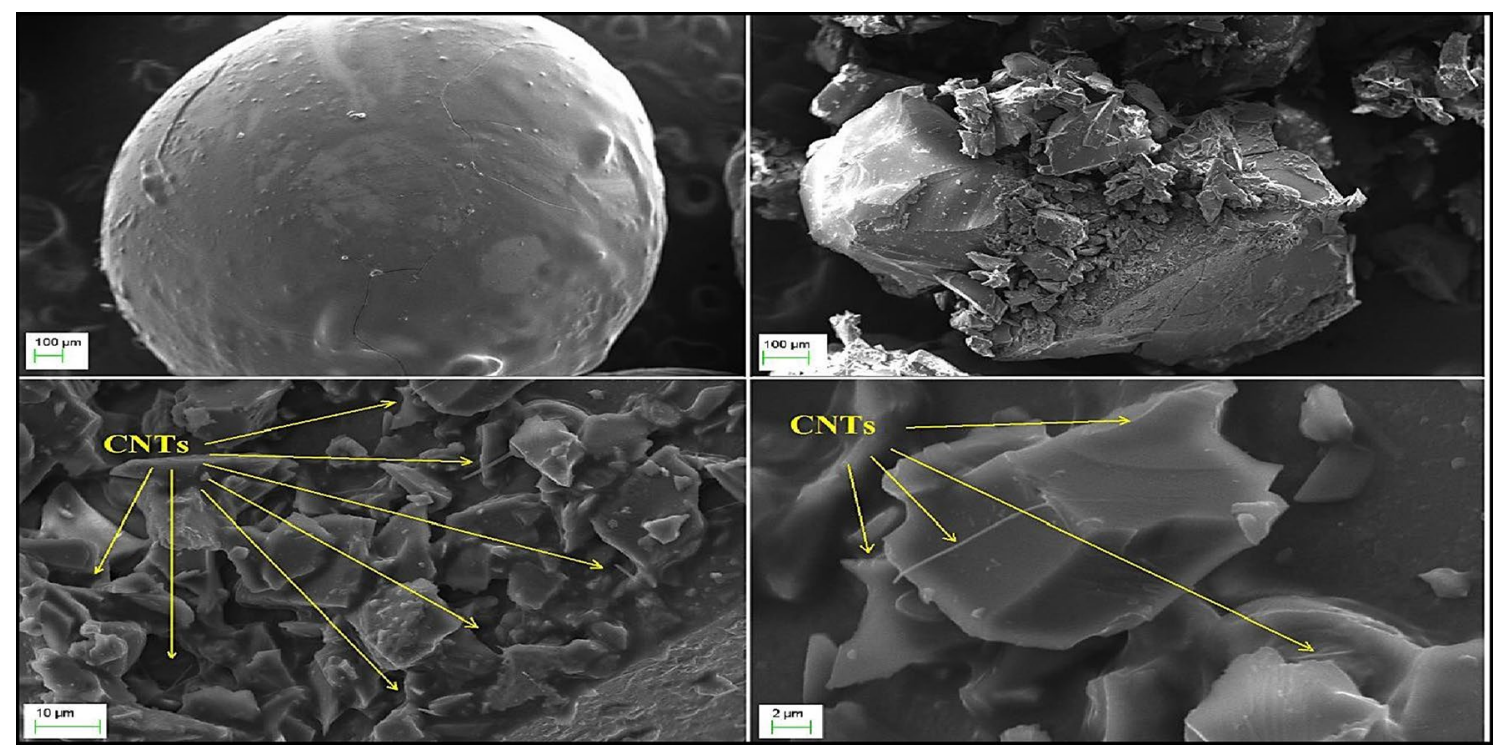

Fig. 9 SEM images of resin based CNTs coated glass bead proppants before and after crush test with different magnifications 
act as reinforcement fibers that effectively distributes the applied load.

\section{Conclusion}

The mechanical strength of glass beads proppants was significantly enhanced by drip coating them with urethane resin that was incorporated with CNT and $\mathrm{rGO}$ which acted as reinforcing fibers. The applied resin coating effectively created a protective polymeric coating around glass proppant grain substrate that reduced proppant crushing thereby inducing mutual adhesion in the form of grain-to-grain bonding making the proppant pack a well-connected mass that effectively distributed the fracture closure stress among the proppant pack body and therefore resisted its crushing and subsequent fines generation. Increasing the loading concentration of CNT and rGO into the urethane resin more than a certain threshold level leads to the phenomenon of agglomeration. Van der Waals forces are the main attraction force responsible for CNTs agglomeration, whereas in the case of rGO, presence of hydrogen bonding causes its agglomeration. Agglomeration of CNTs and rGO forms uneven coating layer on the proppant substrate that fails to effectively distribute the applied loads leading to crushing of the proppant at lower compressive loads. The best result was evinced by $0.5 \mathrm{wt} \%$ CNTs loading into urethane coating that improved the compressive load strength by $84 \%$ when compared with uncoated glass bead proppant and also twice that of the compressive strength rendered by optimum $0.1 \mathrm{wt} \%$ rGO- urethane coating.

Acknowledgements The authors profoundly thank Universiti Teknologi Petronas (UTP), Malaysia to grant the required research support.

Funding This research work was financially supported under YUTPFRGS 015LC0-086 Research grant.

\section{Declarations}

Conflict of interest The authors declare that they have no known competing financial interests or personal relationships that could have appeared to influence the work reported in this research paper.

Ethical statement The authors assure that this manuscript manifests original research work that truly reflects their research analysis in a truthful manner.
Open Access This article is licensed under a Creative Commons Attribution 4.0 International License, which permits use, sharing, adaptation, distribution and reproduction in any medium or format, as long as you give appropriate credit to the original author(s) and the source, provide a link to the Creative Commons licence, and indicate if changes were made. The images or other third party material in this article are included in the article's Creative Commons licence, unless indicated otherwise in a credit line to the material. If material is not included in the article's Creative Commons licence and your intended use is not permitted by statutory regulation or exceeds the permitted use, you will need to obtain permission directly from the copyright holder. To view a copy of this licence, visit http://creativecommons.org/licenses/by/4.0/.

\section{References}

Barati R, Liang JT (2014) A review of fracturing fluid systems used for hydraulic fracturing of oil and gas wells. J Appl Polym Sci. https://doi.org/10.1002/app.40735

Cooke CE (1977) Fracturing with a high-strength proppant. J Pet Technol. https://doi.org/10.2118/6213-PA

De Campos VPP, Sansone EC (2018) Hydraulic fracturing proppants (Propantes para fraturamento hidráulico). Cerâmica 64:219-229

Haque MH, Saini RK, Sayed MA (2019) Nano-composite resin coated proppant for hydraulic fracturing. Proc Annu Offshore Technol Conf. https://doi.org/10.4043/29572-ms

Hussain H, McDaniel RR, Callanan MJ (2015) Proppants with fiber reinforced resin coatings $2(12)$

ISO 8894-2 (2006) International Standard International Standard. 61010-1@Iec2001, vol 2006, p 13

Liang F, Sayed M, Al-Muntasheri GA, Chang FF, Li L (2016) A comprehensive review on proppant technologies. Petroleum 2(1):2639. https://doi.org/10.1016/j.petlm.2015.11.001

Pangilinan KD, De Leon ACC, Advincula RC (2016) Polymers for proppants used in hydraulic fracturing. J Petrol Sci Eng. https:// doi.org/10.1016/j.petrol.2016.03.022

Speight JG (2016) Proppants. In: Handbook of hydraulic fracturing: speight/handbook of hydraulic fracturing, Chapter 6, pp 195-215. https://doi.org/10.1002/9781119225102.ch7

Tabatabaei M, Taleghani AD, Cai Y, Santos LY, Alem N (2019) Using nanoparticles coating to enhance proppant functions to achieve sustainable production. Proc SPE Annu Tech Conf Exhib. https:// doi.org/10.2118/196067-ms

Tran PD, Batabyal SK, Pramana SS, Barber J, Wong LH, Loo SCJ (2012) A cuprous oxide-reduced graphene oxide ( $\mathrm{Cu} 2 \mathrm{O}-\mathrm{rGO})$ composite photocatalyst for hydrogen generation: employing $\mathrm{rGO}$ as an electron acceptor to enhance the photocatalytic activity and stability of Cu 2O. Nanoscale. https://doi.org/10.1039/c2nr30881a

Zoveidavianpoor M, Gharibi A (2015) Application of polymers for coating of proppant in hydraulic fracturing of subterraneous formations: a comprehensive review. J Nat Gas Sci Eng 24:197-209. https://doi.org/10.1016/j.jngse.2015.03.024 